\title{
Bovine Hydatidosis and its Economic Importance at Kara-Alo Abattoir PLC, Addis Ababa, Ethiopia
}

\author{
Getachew Demissie $^{1 *}$ and Jelalu Kemal ${ }^{2}$
}

${ }^{1}$ Addis Ababa City Urban Agricultural Bureau, Addis Ababa, Ethiopia

${ }^{2}$ College of Veterinary Medicine, Haramaya University, Ethiopia

\begin{abstract}
The study was carried out from November 2013-April 2014 with the aim of elucidating the prevalence, assess the risk factors and economic significance of hydatidosis in cattle slaughtered at Kara-alo abattoir, Addis Ababa, involving gross post mortem inspections of organs. Single proportion sample size determination was made to calculate the sample size and a total 768 cattle were randomly inspected. Cyst size, viability test, rate of calcification and fertility as well as sterility was done. In the current study $25.7 \%$ (197/768) prevalence of hydatidosis was recorded. The highest prevalence was observed in the lung $(19.5 \%)$ followed by liver $(12.6 \%)$ while the least was recorded in the kidney $(0.7 \%)$. Small sized cysts contribute nearly $18 \%$ and the majorities were mixed $(79.2 \%)$. Non calcified, fertile and viable cysts contributes $55.9 \%, 39.10 \%$ and $37.7 \%$, respectively. Infection of hydatidosis was significantly higher $(p<0.05,0.002)$ in adults compared to the young cattle. Medium and good body sized cattle were protected from hydatidosis infection compared to poor body condition with a significant difference $(P<0.05,0.0001)$. Age and body conditions of the animals were found to be the risk factors for hydatidosis infections. The financial loss recorded in the current study was 22010 ETB (USD 1158.105). It can be affirmed that hydatidosis is one of the most economically important cattle disease in the area.
\end{abstract}

Keywords: Cattle; Cyst; Economic loss; Hydatidosis; Prevalence; Kara-Alo

\section{Introduction}

Cystic echinococcosis (CE) or cystic hydatidosis is the name given to the condition caused by the zoonotic endoparasitic tapeworm, Echinococcus granulosus. As with all members of the Family Taeniidae, E. granulosus requires two mammalian hosts for completion of its life cycle: a definitive host which is always a carnivore and where the adult worm develops in the small intestine, and an intermediate host which is often a herbivore, where the cystic metacestode usually develops in the visceral organs [1].

As E. granulosus has low intermediate host specificity, infections have been reported from domestic and wild ungulates, particularly bovids, as well as primates, and macro-pod marsupials [1]. In view of this, currently nine different host-adapted genotypes (G1-G9) have been identified using mtDNA sequences, the majority of which are known to be zoonotic apart from the buffalo strain (G3), horse strain (G4) and lion strain (G9) [1-3]. In the definitive host, specificity appears to be far greater than at the intermediate host level although it is often the dog and other canids who act as the definitive host, apart from the G9 lion strain which only involves felids [2]. Although considerable research has been undertaken in relation to the factors responsible for the differences in definitive host specificity, the dynamics are still not completely understood $[2,4]$.

Further research also suggests that male canids are more likely to be infected with Echinococcus spp. than females [5], and that immunosuppressed definitive hosts are more susceptible to infection [6] Research data also indicates that naturally-induced protective immunity may occur as a consequence of infection, thus resulting in considerably lower worm burdens in older Simon D Swanton and John D Wildsmith definitive hosts than those younger hosts who have not yet acquired any immunity [7]. Although E. granulosus has sylvatic cycles, often involving wild carnivores and ungulates, it is the domestic cycles that usually involve dogs and farm livestock that are the most common and pose the greatest risk to human health $[8,9]$.
Even though hydatidosis has been known and documented in Ethiopia as early as 1970, it is still the major cause of organ condemnation in most Ethiopian abattoirs and lead to huge economic losses to the livestock industry [10]. Several reports had indicated that hydatidosis is widely prevalent in livestock population of various regions of Ethiopia [11] but its status was not known in Kara-alo abattoir which is found in Addis Ababa, Ethiopia where raw beef consumption and feeding stray dogs with condemned organs are common practices in the area. Keeping the disease public health significance, understanding of the disease situation by investigating the prevalence and evaluating its economic losses has a great relevance to the country. This in turn will help to establish appropriate control measures. Therefore, the objectives of the present study were to determine the prevalence of bovine hydatidosis, assess the direct economic significance, determine the fertility status and organ distribution of the hydatid cysts and identify possible risk factors associated with the prevalence of the disease in Kara-alo abattoir.

\section{Materials and Methods}

\section{Study area}

The study was conducted from November 2013 - April 2014 in Kara-alo abattoir Plc which is found in Addis Ababa city. Addis Ababa is located at $9^{\circ} 3^{\prime}$ North, latitude and $38^{\circ} 43^{\prime}$ East, longitude.

*Corresponding author: Getachew Demissie, Addis Ababa City Urban Agricultural Bureau, Addis Ababa, Ethiopia, Tel: +251-25-5530334, +251-25-5530060; E-mail: gech.demis@gmail.com

Received August 08, 2014; Accepted November 26, 2014; Published November 28,2014

Citation: Demissie G, Kemal J (2014) Bovine Hydatidosis and its Economic Importance at Kara-Alo Abattoir PLC, Addis Ababa, Ethiopia. J Veterinar Sci Technol 5: 206. doi:10.4172/2157-7579.1000206

Copyright: @ 2014 Demissie G, et al. This is an open-access article distributed under the terms of the Creative Commons Attribution License, which permits unrestricted use, distribution, and reproduction in any medium, provided the original author and source are credited. 
It lies in the central highlands of Ethiopia at an altitude of $2500 \mathrm{~m}$ above sea level. It has an average rainfall of $1800 \mathrm{~mm}$ per annum. The annual average maximum and minimum temperature is $26^{\circ} \mathrm{C}$ and $11^{\circ} \mathrm{C}$, respectively: with an overall average of $18.7^{\circ} \mathrm{C}$. The main rainy season extends from June to September. Addis Ababa has a relative humidity ranging from $70-80 \%$ during rainy season and 40 $50 \%$ during dry season. The human population is estimated at about 3 million inhabitants [12].

\section{Study population}

Bovines slaughtered in kara-alo abattoir were used as the study animal. Cattle's were brought from different parts of the country namely; Dessie, Kemissie, North showa, Ambo, Arsi, Bale, Borena, Harar, Adama, Guragae area etc.

\section{Study design}

Cross-sectional study design was conducted in the kara-alo abattoir PLC involving gross postmortem inspections. Information like origin, body conditions, age, sex, species and lesions distribution as well as nature of the cyst was recorded using standard format before and after slaughter, respectively.

\section{Sampling method and sample size determination}

Cattle were picked randomly till the required sample size met. The sample size was calculated using the formula given by Thrusfield [13] with $50 \%$ expected prevalence and $5 \%$ accepted error at $95 \%$ confidence interval.

$$
\mathrm{N}=\frac{1.96^{2} \times \operatorname{pexp}(1-\mathrm{pexp})}{\mathrm{d}^{2}}
$$

Where: $\mathrm{N}=$ required sample size

Pexp $=$ expected prevalence

\section{$\mathrm{d}=$ desire absolute precision}

Therefore, by substituting the value in the given formula $\mathrm{n}=384$ were used as representative animal for this study. But due to need of increased sample size 768 (two fold) cattle were inspected.

\section{Abattoir survey}

Before inspection commencement the age of slaughtered animals were determined. The abattoir survey was conducted in routine examination of randomly selected cattle at the study area. A thorough post-mortem examination was conducted on animals slaughtered at municipal abattoir. The lungs, liver, heart, spleen and kidneys were examined. Echinococcus cysts identified was removed and collected in polyethylene bags or Petri-dish. Each polyethylene bag or Petri-dish was used for hydatid cysts obtained from one animal and was labeled appropriately to show the species. The cysts were transported to the nearest laboratory and examined within one hour.

\section{Cyst fertility and viability test}

Individual cysts were grossly examined for any evidence of degeneration and calcification. Cysts were selected for fertility studies and to reduce intra-cystic pressure, the cyst wall was penetrated with a needle and opened up with a scalpel and scissors. The contents was then be transferred into a sterile container and examined microscopically $(40 \times)$ for the presence of protoscoleces. Cysts, which were not containing any protoscoleces as well as heavily suppurative or calcified, were considered unfertile. The viability of protoscoleces was assessed by the motility of flame cells together with staining with a $0.1 \%$ aqueous eosin solution. Living protoscoleces did not take up the stain, unlike the dead ones [14].

\section{Financial assessment}

To study the direct financial loss due to hydatidosis at the abattoir was computed by multiplying the average number of cattle slaughter annually with the prevalence of hydatidosis and with mean price of condemned organ in the town. To calculate the price of liver, lung, spleen, heart, and kidney the data was randomly collected from meat sellers \& determine mean price. The average annual slaughter rate of cattle at the abattoir also determined based on retrospective analysis of data recorded from three years. An annual direct economic cost was estimated according to Zewdu [15] using the formula: Annual direct economic loss $=\left(\mathrm{pI}_{1} \mathrm{xT}_{\mathrm{k}} \mathrm{xc}_{1}\right)+\left(\mathrm{pI}_{2} \mathrm{xT}_{\mathrm{k}} \mathrm{xc}_{2}\right)+\left(\mathrm{pI}_{3} \mathrm{xT}_{\mathrm{k}} \mathrm{xc}_{3}\right)+\left(\mathrm{pI}_{4} \mathrm{xT}_{\mathrm{k}} \mathrm{xc}_{4}\right)$. $\left(\mathrm{PI}_{1}=\right.$ percent involvement of lung out of total examined, $\mathrm{PI}_{2}=$ percent involvement of liver out of total examined, $\mathrm{PI}_{3}=$ percent involvement of spleen out of total examined, $\mathrm{PI}_{4}=$ percent involvement of heart out of total examined, $\mathrm{C}_{1}=$ average market price of lung, $\mathrm{C}_{2}=$ average market price of liver, $\mathrm{C}_{3}=$ average market price of spleen, $\mathrm{C}_{4}=$ average market price of heart, $\mathrm{T}_{\mathrm{k}}=$ average annual kill of bovines).

\section{Data analysis}

The data obtained was coded in Microsoft excel and subjected to descriptive statistics and chi-square in order to assess the magnitude of the difference of comparable variables using SPSS version 17.0 software. Descriptive statistics was done to determine the prevalence of hydatidosis among different variables. Logistic regression and Chisquare was employed to analyze the association of the occurrence of hydatidosis with the potential risk factors.

\section{Results}

\section{Total and individual prevalence}

In this study 768 male cattle were included and the characteristics of inspected animals were shown (Table 1). The present study revealed an overall bovine hydatidosis prevalence of $25.7 \%(n=197)$. The distribution (prevalence) of hydatid cyst in different organs is presented (Table 2). Of the total inspected cattle $93.5 \%$ were adult age groups and nearly $47 \%$ were having medium body conditions.

As it is shown in Table 2, higher infection rate were recorded in the

\begin{tabular}{|c|c|c|}
\hline Category & Frequency & Percent \\
\hline Age & 50 & 6.5 \\
Young & 718 & 93.5 \\
\hline Adult & $\mathbf{7 6 8}$ & $\mathbf{1 0 0}$ \\
\hline Total & & \\
\hline Body condition & 141 & 18.4 \\
Poor & 360 & 46.9 \\
Medium & $\mathbf{2 6 7}$ & 34.8 \\
\hline Good & $\mathbf{7 6 8}$ & $\mathbf{1 0 0}$ \\
\hline Total & & \\
\hline
\end{tabular}

Table 1: Characteristics of inspected cattle in Kara-alo abattoir Plc, Addis Ababa November 2013-April 2014

\begin{tabular}{|c|c|c|c|c|}
\hline Organ & Negative & $\%$ & Positive & $\%$ \\
\hline Lung & 618 & 80.5 & 150 & 19.5 \\
Liver & 671 & 87.4 & 97 & 12.6 \\
Kidney & 763 & 99.3 & 5 & 0.7 \\
Heart & 758 & 98.7 & 10 & 1.3 \\
Spleen & 755 & 98.3 & 13 & 1.7 \\
\hline
\end{tabular}

Table 2: Distribution of bovine hydatidosis in different organs of inspected cattle in Kara-alo abattoir PLC, Addis Ababa. 
lung followed by the liver. Lowest anatomical infection rate found in the kidney compared to other organs.

As presented in Table 3, 79.20\% of the cysts were having mixed size comprised of either small and large, small and medium or large and medium or a combination of small, medium and large. Of the rest small sized ones contributed nearly about $18 \%$. The least was large size that is $0.51 \%$. Majority of the cysts $64.5 \%$ were non calcified. Nearly $72.7 \%$ and $62.2 \%$ of the cysts were infertile and nonviable, respectively.

Infection of hydatidosis was higher in adult cattle compared to young cattle and the difference was significant $(\mathrm{X} 2=5.23)(\mathrm{p}<0.05$, 0.002 ). Cattle having poor body condition harbored more hydatid cysts compared to those having medium and good body conditions, and the difference was significant, $(\mathrm{X} 2=35.7)(\mathrm{P}<0.05,0.0001)$. Similarly cyst infections were significantly associated with all anatomically inspected organs with a higher proportion of the lungs followed by the liver (Table $4)$.

The average slaughtered bovine in Karo-alo PLC abattoir was 175 (average slaughtered per day). The average loss registered in this study was 11005.00 birr (Table 5), but using the formula given in the methodology part the direct financial loss occurred in the abattoir excluding condemned spleen was 22010 ETB (USD 1158.105).

\begin{tabular}{|l|c|c|}
\hline Category & Number & Percent \\
\hline Cyst size $(\mathbf{n = 1 9 7 )}$ & 35 & 17.77 \\
Small & 5 & 2.53 \\
Medium & 1 & 0.50 \\
Large & 156 & 79.2 \\
\hline Mixed & & \\
\hline Total cyst $(\mathbf{n = 7 2 2 )}$ & 256 & 35.5 \\
Calcified & 466 & 64.5 \\
Non-Calcified & & \\
\hline Status of fertility $(\mathbf{n = 4 6 6 )}$ & 127 & 27.3 \\
Fertile & 339 & 72.7 \\
\hline Infertile & & \\
\hline Status of viability $\mathbf{( n = 1 2 7 )}$ & 48 & 37.8 \\
Viable & 79 & 62.2 \\
Nonviable & & \\
\hline
\end{tabular}

Table 3: Characteristics of inspected cysts in Kara-alo abattoir PLC, Addis Ababa.

\begin{tabular}{|l|c|c|c|c|c|}
\hline Category & $\begin{array}{c}\text { Number } \\
\text { Examined }\end{array}$ & Negative & Positive & Chi-square & Sig \\
\hline Age & 50 & 44 & 6 & 5.23 & 0.002 \\
\hline Young & 718 & 527 & 191 & & \\
\hline Adult & 768 & 571 & 197 & & \\
\hline Total & & & & & \\
\hline Body condition & 141 & 79 & 62 & 35.7 & 0.0001 \\
\hline Poor & 360 & 270 & 90 & & \\
\hline Medium & 267 & 222 & 45 & & \\
\hline Good & 768 & 571 & 197 & & \\
\hline Total & & & & & \\
\hline Organ distribution & 768 & 618 & 150 & 540.3 & 0.0001 \\
\hline Lung & 768 & 671 & 97 & 321.8 & 0.0001 \\
\hline Liver & 768 & 763 & 5 & 14.6 & 0.001 \\
\hline Kidney & 768 & 758 & 10 & 29.4 & 0.0001 \\
\hline Heart & 768 & 755 & 13 & 38.3 & 0.0001 \\
\hline Spleen & & & & \\
\hline Table $4:$ The & & & & \\
\hline
\end{tabular}

Table 4: The association of hydatidosis with different predictors using Chi-square test in Kara-alo abattoir PLC, Addis Ababa.

\begin{tabular}{|c|c|c|c|}
\hline Organ & Number condemned & Average unit price in Birr & Total average loss \\
\hline Heart & 10 & 20 & 200 \\
\hline Kidney & 5 & 40 & 200 \\
\hline Liver & 97 & 70 & 6790 \\
\hline Lung & 150 & 25 & 3750 \\
\hline Spleen & 13 & 5 & 65 \\
\hline Total & $\mathbf{2 7 5}$ & $\mathbf{1 6 0}$ & $\mathbf{1 1 0 0 5}$ \\
\hline
\end{tabular}

Table 5: Average financial loss due to organ condemnation from November 2013-April 2014 in Kara-alo PLC abattoir Addis Ababa.

\section{Discussion}

In this study a prevalence of $25.7 \%$ of hydatidosis were recorded. A study carried out in Dessie, Arbaminch, Tigray, Bahir Dar and Addis Ababa municipal abattoir revealed $13.6 \%, 20.5 \%, 22 \%, 31.8 \%$ and $40.5 \%$ of hydatidosis prevalence, respectively [11,16-18]. The difference in the prevalence of hydatidosis in different areas including this study could be related to the source of cattle, geography, dog population, dog management as well as deworming practices, offal disposal habits and age of cattle slaughtered. Slaughtered cattle for Kara-alo abattoir came from different corners of the country with possibility of varying degree of infection rate compared to relatively limited cattle sources.

Generally, the variations in prevalence among different geographic location is attributed to the strain difference of E. granulosus exists in different geographical situation [19]. The prevalence may be generally related to the presence of favorable factors for the propagation and maintenance of high level of infection in the area, and particularly it may be where recorded at ascribed to the origin of the slaughtered animals, which majority of positive cases, where recorded at Addis Ababa, where the environmental conditions such as low temperature and high humidity (suitable condition for the survival of the egg of $E$. granulosus) exist. However, the age of the slaughtered animals is also anticipated as one of the reason contributing to the high prevalence of the disease in the area.

In the current study hydatidosis infection was associated with the body condition of inspected cattle. Poor, medium and good body conditioned cattle were infected by $44 \%, 25 \%$ and $17 \%$, respectively and the difference was statistically significant $(p<0.05,0.0001)$. Although the proportion differs a similar infection trend was reported in a study conducted in Dessie municipal abattoir [16]. Age (adults were more affected) and body weight (Poor body conditioned ones were more affected that medium and good) of bovines in the current study were the contributing factors for hydatidosis infections.

In this cross sectional study anatomical infection rate of $19.53 \%$, $12.63 \%, 0.70 \%, 1.30 \%$ and $1.70 \%$ was registered in the lungs, liver, kidney, heart and spleen, respectively. Contrary to the current finding in Dessie municipal abattoir higher infection rates were reported in the lung and kidney, while it was almost closely similar finding in the liver and heart. This might be attributed to the differences in age and the body condition of slaughtered cattle as well as most likely immunity status of individual cattle. In Kara-alo PLC abattoir 35.5\%, 64.5\%, $27.3 \%, 72.7 \%, 37.8 \%$ and $62.2 \%$ of calcified, non-calcified, fertile, sterile/infertile, viable and non-viable cysts were recorded, respectively. The current finding revealed higher proportions of cyst calcification, viability as well as fertility. Nearly similar percentage of sterile cyst finding was registered in Dessie municipal abattoir [16]

The condition of hydatid cyst recorded during the survey period indicated that a lower percentage of fertility was identified of the total cyst examined and relatively higher percentage, of the total cyst were 
found sterile and calcified respectively. Of the total recovered cysts the fertile cysts were lower and this may be attributed to the strain of $E$. granulosus which showed the importance of cattle in maintaining the cycle in minimal level. Moreover, the variation in fertility, sterility and calcification was described as strain difference of E. granulosus involved may be, if that of sheep strain which results to sterile cyst when occurred in cattle. Arene [19] and Mcmanus and Smith [20] stated that strain of parasite and host can modify the infectivity of the parasites. As to the size of the cyst, higher number of medium and large sized cyst found in the lung is due to the soft consistence of the organ.

The current study indicated that the annual economic loss incurred due to organ condemnation as a result of hydatidosis was estimated to be $22,010 \mathrm{ETB}$, which is equivalent to (USD 1,158.105). In Dessie and Arbaminch municipal abattoirs an annual total loss of 681,333.87 $\operatorname{ETB}(39,157.12, \mathrm{USD})$ and 21,833.60, USD, respectively were reported. Compared to Dessie and Arbaminch municipal abattoirs financial loss estimation, the higher estimated financial loss in the current study could be related to the average number of killed bovines per annum was too much in Kara-alo abattoir PLC.

\section{Conclusion}

Bovine hydatidosis is not only a disease of animals; it is also a problem to the public since it has zoonotic implications. The study revealed the presence of hydatidosis in bovines slaughtered in Karaalo PLC abattoir. Body conditions as well as age were found as the risk factors for hydatidosis infections. Lung and liver were the major organs condemned in the study site and the financial loss due to different organ condemnation was paramount importance.

\section{References}

1. Thompson RCA, McManus DP (2001) Aetiology: parasites and life-cycles, in WHO/OIE Manual on Echinococcus in humans and animals: A public health problem of global concern. World Health Organisation, Geneva/World Organisation for Animal Health, Paris.

2. Thompson RCA (1995) Biology of Echinococcus and Hydatid Disease. CAB International, Wallingford.

3. Eckert J, Deplazes P (2004) Biological, epidemiological, and clinical aspects of echinococcosis, a zoonosis of increasing concern. Clin Microbiol Rev 17: 107-135.

4. Buishi IE, Njoroge EM, Bouamra O, Craig PS (2005) Canine echinococcosis in northwest Libya: assessment of coproantigen ELISA, and a survey of infection with analysis of risk-factors. Vet Parasitol 130: 223-232.

5. Gasser RB, Lightowlers MW, Obendorf DL, Jenkins DJ, Rickard MD (1988) Evaluation of a serological test system for the diagnosis of natural Echinococcus granulosus infection in dogs using $\mathrm{E}$. granulosus protoscolex and oncosphere antigens, Australian Veterinary Journal. 65: 369-373.
6. Sato H, Kamiya M (1990) Establishment, development and fecundity of Taenia crassiceps in the intestine of prednisolone-treated Mongolian gerbils and inbred mice. J Helminthol 64: 217-222.

7. Lahmar S, Boufana B, Bradshaw H, Craig PS (2006) Screening fo Echinococcus granulosus in dogs: Comparison between arecoline purgation, coproELISA and copro PCR with necropsy in pre-patent infections, Veterinary Parasitology, 130: 212-217.

8. Eckert J, Gemmell MA, Meslin FX, Pawlowski ZS (2001) Manual on Echinococcus in humans and animals: A public health problem of global concern. World Health Organisation, Geneva/World Organisation for Animal Health, Paris.

9. McManus DP, Zhang W, Li J, Bartley PB (2003) Echinococcosis. Lancet 362 1295-1304.

10. Hagos D (1997) Tigray Livestock Development Action Program. Tigray Bureau of Agriculture and Natural Resource Development: Mekelle. mimeo

11. Kebede W, Hagos A, Girma Z, Lobago F (2009) Echinococcosis/hydatidosis its prevalence, economic and public health significance in Tigray region, North Ethiopia. Trop Anim Health Prod 41: 865-871.

12. Central Statistical Agency of Ethiopia (CSA) (2003) Estimated number of cattle sheep and goats by region: 2008/2009 (private peasant holdings for rural only), CSA, Addis Ababa.

13. Thrusfield M (2005) Veterinary Epidemiology. 3 ed. Blackwell science Ltd. London. 228-246.

14. Macpherson JM, Horak FB, Dunbar DC, Dow RS (1989) Stance dependence of automatic postural adjustments in humans. Exp Brain Res 78: 557-566.

15. Zewdu E, Yechale T, Assefa M (2010) Bovine Hydatidosis in Ambo Municipality Abattoir, West Shoa, Ethiopia. Ethiop. Vet J 14: 1-14.

16. Woubet S (1988) Prevalence of hydatidosis and its economic significance in Dire Dawa abattoir. DVM thesis, FVM, AAU, Debre Zeit Ethiopia. 12.

17. Kebede N, Mitiku A, Tilahun G (2009) Hydatidosis of slaughtered animals in Bahir Dar Abattoir, Northwestern Ethiopia. Trop Anim Health Prod 41: 43-50.

18. Dechassa T, Kibrusfaw K, Desta B, Anteneh W (2012) Prevalence and financial loss estimation of hydatidosis of cattle slaughtered at Addis Ababa abattoirs enterprise. Journal of Veterinary Medicine and Animal Health 4: 42-47.

19. Arene FO (1985) Prevalence of hydatid cysts in domestic livestock in the Niger Delta. Trop Anim Health Prod 17: 3-5.

20. McManus DP, Smyth JD (1986) Hydatidosis: changing concepts in epidemiology and speciation. Parasitol Today 2: 163-168. 